\title{
Dispersal of Formulations of Fusarium oxysporum f. sp. erythroxyli and $F$. oxysporum f. sp. melonis by Ants
}

\author{
J. A. Gracia-Garza, D. R. Fravel, B. A. Bailey, and P. K. Hebbar
}

USDA-ARS, Biocontrol of Plant Diseases Laboratory, Beltsville Agricultural Research Center, Beltsville, MD 20705. Accepted for publication 26 November 1997.

\begin{abstract}
Gracia-Garza, J. A., Fravel, D. R., Bailey, B. A., and Hebbar, P. K. 1998. Dispersal of formulations of Fusarium oxysporum f. sp. erythroxyli and F. oxysporum f. sp. melonis by ants. Phytopathology 88:185-189.

A natural epidemic of Fusarium wilt on coca (Erythroxylum coca) in Peru prompted the suggestion of possibly using the pathogen Fusarium oxysporum f. sp. erythroxyli as a mycoherbicide against this narcotic plant. During field trials conducted in Kauai, HI, to test the pathogenicity of the coca wilt pathogen, ants were observed removing formulations from test plots. While removal of formulations by ants was considered detrimental with respect to conducting field tests, ant removal was considered potentially beneficial in disseminating the mycoherbicide. Thus, research was initiated to assess the ability of formulation additives to alter the preference of ants for the formulated mycoherbicide. In Hawaii, preference of indigenous ants for removing formulations was tested using three different food bases (rice, rice plus canola oil, and wheat flour [gluten]). Similar tests were conducted at Beltsville, MD, using F. oxysporum f. sp. melonis, in which the formulation based on wheat flour was replaced by a formulation based on canola meal. Formulations based on wheat were preferred by ants in both locations; up to $90 \%$ of the

wheat plus rice flour granules (C-6) and the wheat gluten plus kaolin granules (pesta) were removed within $24 \mathrm{~h}$, while only $20 \%$ of those containing rice without oils were taken. However, when either canola, sunflower (Maryland only), or olive oil was added to the rice formulation, up to $90 \%$ of the granules were taken. The formulation based on canola meal was less attractive to ants, as only $65 \%$ of the granules were removed within a period of $24 \mathrm{~h}$. Ants showed no preference with respect to presence or absence of fungal biomass. To alter the attractiveness of the C-6 formulation to ants, C-6 was amended with three natural products. Canna and tansy leaves were added to C-6 at a ratio of 1:5 (wt/wt), while chili powder was added at 1:25 or 1:2.5 (wt/wt). Canna, tansy, and the higher rate of chili powder significantly reduced the number of C-6 granules removed by ants. Canna and tansy leaves affected neither germination nor sporulation of the mycoherbicide, while the high concentration of chili powder reduced viability of propagules in the formulation. More $F$. oxysporum f. sp. erythroxyli-type colonies were recovered from inside ant nests $(9 \mathrm{~cm}$ depth) than from nest surfaces, indicating that ants may distribute the mycoherbicide in the soil profile. Ants passively carried propagules of $F$. oxysporum f. sp. erythroxyli outside their bodies, as well as either very closely adhering to the outside or within their bodies.
\end{abstract}

Fusarium oxysporum Schlechtend.:Fr. f. sp. erythroxyli causes a wilt disease of the narcotic plant Erythroxylum coca Lam. var. coca. Currently, an epidemic of this disease is occurring on coca in regions of Peru, and the disease has also been reported in Hawaii $(1,2,19)$. The potential of this fungus as a mycoherbicide for use against coca is being investigated. When experiments using various formulations of the mycoherbicide were first established in Hawaii, formulation granules were removed by ants, interfering with the delimitation of the different treatments tested (2). Ant movement of formulations on the soil surface and possibly within the soil, however, was not considered to be necessarily detrimental. Dissemination of $F$. oxysporum f. sp. erythroxyli by ants within the soil profile might enhance its survival compared with formulations remaining on the soil surface. Furthermore, transport of the formulation into the soil may place the mycoherbicide in a more suitable location to facilitate root infection. However, to complete studies of biocontrol of coca, it was necessary to identify methods to deter removal of formulations of the mycoherbicide by ants. The objectives of this research were to identify formulation addi-

Corresponding author: D. R. Fravel; E-mail address: dfravel@asrr.arsusda.gov

Mention of a trademark or proprietary product does not constitute a guarantee of the product by the U.S. Department of Agriculture, and does not imply its approval to the exclusion of other products that may also be suitable.

Publication no. P-1997-1222-01R

This article is in the public domain and not copyrightable. It may be freely reprinted with customary crediting of the source. The American Phytopathological Society, 1998. tives that alter attractiveness of the formulations to ants, but are not toxic to $F$. oxysporum f. sp. erythroxyli, and to assess the capacity of ants to disperse formulations of the mycoherbicide $F$. oxysporum f. sp. erythroxyli.

\section{MATERIALS AND METHODS}

Effect of food base on ant attraction to formulations of $\boldsymbol{F}$. oxysporum f. sp. erythroxyli and $F$. oxysporum f. sp. melonis. A series of tests were carried out in Beltsville, MD, and Kauai, HI, to determine the effect of food bases in formulations of $F$. oxysporum on their attractiveness to ants. Because $F$. oxysporum $\mathrm{f}$. sp. erythroxyli is an exotic strain that does not occur in the continental United States, tests conducted at Beltsville, MD, were performed with formulations of isolate $\mathrm{F} 1$ of $F$. oxysporum $\mathrm{f}$. sp. melonis W.C. Snyder \& H.N. Hans. indigenous to Maryland. The presence of biomass of different formae speciales of $F$. oxysporum in the formulations should not affect the attractiveness of formulations to ants, because this taxonomic classification among formae speciales is only based on host specificity and not on morphological characteristics. In tests in Hawaii, F. oxysporum f. sp. erythroxyli isolate EN-4 was used in all formulations. This isolate was isolated from a coca field on the island of Kauai, HI (22). All formulations contained chlamydospores $\left(10^{7}\right.$ to $10^{8}$ chlamydospores per g of dry formulation) of $F$. oxysporum f. sp. erythroxyli (Hawaii) or F. oxysporum f. sp. melonis (Maryland). Four granular formulations (treatments) were used in tests in Maryland: (i) a granular extrusion of wheat plus rice flour (C-6); (ii) an alginate granule of canola meal (canola); (iii) an alginate granule of rice flour (rice); and (iv) an alginate granule of rice flour plus canola 
oil (rice plus oil) (9). In tests in Hawaii, the canola formulation was replaced by a granular extrusion of wheat gluten plus kaolin (pesta) (5). To determine the effect of fungal biomass on the attractiveness of the formulation to ants, granules with and without biomass of $F$. oxysporum f. sp. erythroxyli were included in some tests in Hawaii. In Maryland, most $(>80 \%)$ ants were Pheidole spp., and these were the only ants observed removing formulations. Similarly, in the Hawaiian field plots, most ants were $P$. megacephala (Fabricius), and these were the only ants removing formulations $(3,12)$.

Each treatment formulation was added to each of three $1-\mathrm{m}^{2}$ noncontiguous blocks established in fields in both Hawaii and Maryland. Ten granules of each treatment were placed on the surface of the soil in each block at 6:30 a.m. in Hawaii or 9:00 a.m. in Maryland. Visual observation of blocks indicated that ants alone were responsible for removal of formulation granules. Every $24 \mathrm{~h}$, the number of remaining granules was counted and new granules added as needed to result in 10 granules for each replicate. After an additional $24 \mathrm{~h}$, the remaining granules for each replicate were counted. The two sampling times were considered subsamples. The experiment was repeated in a new area of the field, and treatments were assigned new random positions within each block. The experiment was conducted six times each in Maryland and Hawaii.

Effect of type of oil in formulations on ant preference. To test the hypothesis that oils in the formulations may increase the attractiveness of formulations to ants, because the substrate was perceived as a seed, the C-6 formulation was amended with various types of oils. These oils included sunflower oil (21.3\% oleic acid) (Super G, Inc., Landover, MD), canola oil (60\% oleic acid) (Hunt-Weeson, Inc., Fullerton, CA), and olive oil ( $83.5 \%$ oleic acid) (Pompeian, Inc., Baltimore) (27). Formulations were set in the field in $1-\mathrm{m}^{2}$ blocks using the same experimental designs and procedures as described above. Experiments were conducted six times each in Maryland and Hawaii.

Three days after these formulations were prepared, the viability of the two formae speciales of $F$. oxysporum used was determined. One gram of each formulation was placed in a separate glass tube $(16 \times 150 \mathrm{~mm})$ with $10 \mathrm{ml}$ of a phosphate buffer solution $(\mathrm{pH}$ 7.0). Tubes were shaken for $3 \mathrm{~h}(150 \mathrm{rpm})$ prior to grinding in a blender (Euro Turrax T 20; Janke \& Kunkel GmbH \& Co. KG, Staufen, Germany) for 2 min until granules were totally disinte-

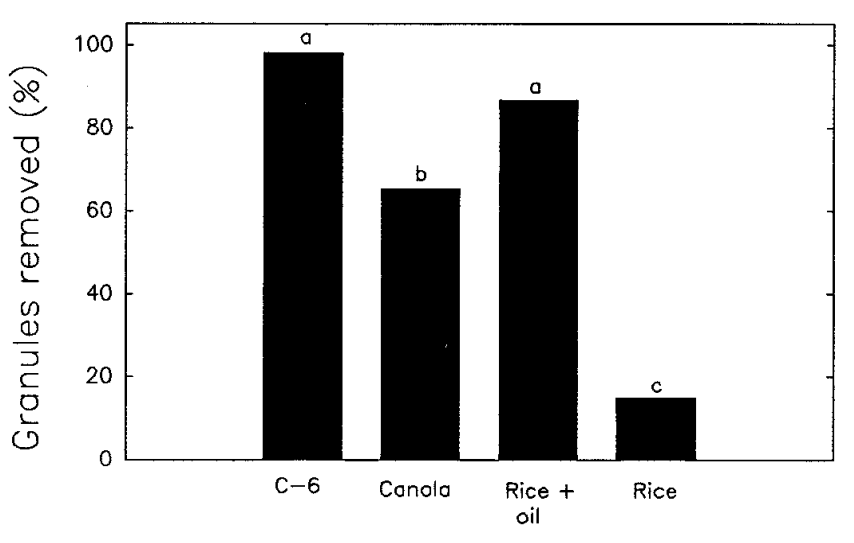

Formulation

Fig. 1. Formulation preference by Pheidole spp. ants in field tests in Beltsville, MD. C $-6=$ extrusion of wheat plus rice flour, canola $=$ alginate granule of canola meal, rice + canola oil $=$ alginate granule of rice flour plus canola oil, and rice $=$ alginate granule of rice flour. Percentage represents the portion of the formulation removed in $24 \mathrm{~h}$. Bars with a different letter differ according to a protected least significant difference test $(P \leq 0.05)$. Means are based on combined data from seven experiments. grated and formed a homogenous dispersion. Ten-fold dilutions were prepared, and $1 \mathrm{ml}$ was plated on a medium semiselective for Fusarium (FSM) (15). Plates were incubated at $22 \pm 2^{\circ} \mathrm{C}$ for 3 days under continuous fluorescent light $(40 \mathrm{~cm}$ from a DLX Cool White bulb; General Electric, Inc., Glen Allen, VA), and the number of colony forming units (CFU) was counted.

Use of natural materials to deter ants from C-6 formulation. Three plant materials previously reported as strong irritants and deterrents to insects (20) were incorporated into the C-6 formulation. Leaves from canna (Canna sp. L.) and tansy (Tanacetum vulgare L.) plants were collected, dried at room temperature for 20 days, and then ground in an analytical mill (Analysenmuhle; Janke \& Kunkel $\mathrm{GmbH} \& \mathrm{Co}$. KG) to pass a $425-\mu \mathrm{m}$-pore-size screen. Commercial chili powder (McCormick \& Co., Hunt Valley, MD) containing chili pepper, red pepper, cumin, oregano, salt, silicon dioxide, and garlic was obtained from a local grocery and used directly from the container. Canna or tansy powder was added at a ratio of 1:5 (wt/wt; $1 \mathrm{~g}$ of plant material in $5 \mathrm{~g}$ of formulation mixture). Chili powder was added in a low $(1: 25 \mathrm{wt} / \mathrm{wt})$ and high $(1: 2.5 \mathrm{wt} / \mathrm{wt})$ concentration. Granules were stored at $4{ }^{\circ} \mathrm{C}$ for no longer than 10 days before use. The effect of these amendments on viability of $F$. oxysporum f. sp. erythroxyli was tested as described above.

These experiments were conducted only in the coca field in Hawaii. As with the preceding tests, three $1-\mathrm{m}^{2}$ blocks were established, and a total of seven treatments were included in each block: (i) nonamended granules (control), (ii) nonautoclaved canna powder, (iii) autoclaved canna powder, (iv) nonautoclaved tansy powder, (v) autoclaved tansy powder, (vi) chili powder low concentration, and (vii) chili powder high concentration. For those treatments with autoclaved canna or tansy powder, plant material was mixed with the other components of the formulation prior to autoclaving. Procedures for the viability and preference tests were as described above. The experiment was conducted six times.

Ant dispersal of $F$. oxysporum f. sp. erythroxyli through soil. These tests were designed to determine whether ants carry granules of the formulation into their nests. At the conclusion of the formulation preference tests described above, soil cores $(2 \mathrm{~cm}$ wide $\times 9 \mathrm{~cm}$ tall $)$ were taken from the entrance of ant nests and then divided into three equal sections, 0 to 3,3 to 6 , and 6 to $9 \mathrm{~cm}$. Samples for each depth category were mixed thoroughly. A 1-g subsample was used to make 10 -fold dilutions that were plated on

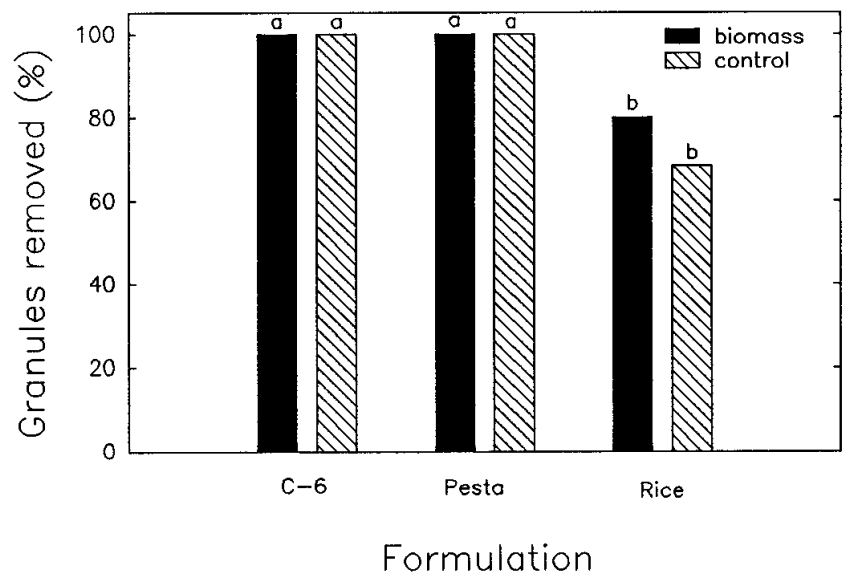

Fig. 2. Formulation preference by Pheidole megacephala ants in field tests in Kauai, HI. C-6 = extrusion of wheat plus rice flour, pesta $=$ extrusion of wheat gluten plus kaolin, rice $=$ alginate granule of rice flour. Biomass $=$ addition of chlamydospores of Fusarium oxysporum f. sp. erythroxyli, and control $=$ no biomass added. Percentage represents the portion of the formulation removed in $24 \mathrm{~h}$. Bars with a different letter differ according to a protected least significant difference test $(P \leq 0.05)$. Means are based on combined data from six experiments. 
FSM. After 5 days of incubation on a greenhouse bench under natural light at $22 \pm 2{ }^{\circ} \mathrm{C}$, the number of $\mathrm{CFU}$ was recorded. The experiment was repeated.

In an additional test, plastic tubs (50 liter volume) were filled with soil (approximately 30 liters), and an ant colony was removed from the soil with a shovel and added to each tub. Five grams of C-6 granules, with or without biomass of $F$. oxysporum f. sp. erythroxyli, was added to the surface of the soil in each tub. There were three replicate tubs for each of two treatments, C-6 granules with biomass and C-6 granules without biomass. One gram of treatment granules was added per tub daily to maintain activity in the colony. After 6 days of ant activity, soil columns $(2 \mathrm{~cm}$ wide $\times$ $8 \mathrm{~cm}$ tall) were removed. Columns were separated into two sections, 0 to 4 and 4 to $8 \mathrm{~cm}$. Population densities of $F$. oxysporum $\mathrm{f}$. sp. erythroxyli were determined as described above.

Ants as carriers of propagules of $F$. oxysporum f. sp. erythroxyli. To determine the ability of ants to be passive carriers of F. oxysporum f. sp. erythroxyli, ants were collected from colonies contained in tubs. Out of a total of 50 ants collected from each treatment, 25 were used to determine presence of the fungus on the outside of the bodies, and the remaining 25 were used to test for presence of the fungus either adhering very closely to the ants or inside the ants. One ant was placed in a microcentrifuge tube ( $1.5 \mathrm{ml}$ capacity) with $1 \mathrm{ml}$ of sterile distilled water and vortexed for 1 min to check for external contamination by the pathogen; the water was withdrawn immediately after vortexing and plated onto FSM. Plates were incubated for 5 days as described above, and the number of CFU was recorded. Because of their body openings (mouth, anus, and spiracles) and permeability between body segments, ants could not be surface-disinfested. To determine if ants carried the mycoherbicide either within their bodies or tightly adhering to the outside of their bodies, ants were washed twice by vortexing as described above, collected from the tube, and pressed directly into a plate of FSM. Plates were incubated for 10 days. Samples were recorded as positive or negative for presence of $F$. oxysporum f. sp. erythroxyli. The experiment was repeated.

Statistical analysis. All experiments were performed at least two times. Data were statistically analyzed using the general linear model procedures of SAS (SAS Institute, Cary, NC), and each experiment was analyzed individually (23). However, because variances were homogenous and results were similar among repetitions of the experiments, data from all repetitions of a test were combined for presentation of the results. In the food base, oil type, natural products, and ants as carrier experiments, means were separated using the protected least significant difference test. For the ant dispersal experiment, differences among the three soil depth categories were separated using orthogonal contrasts.

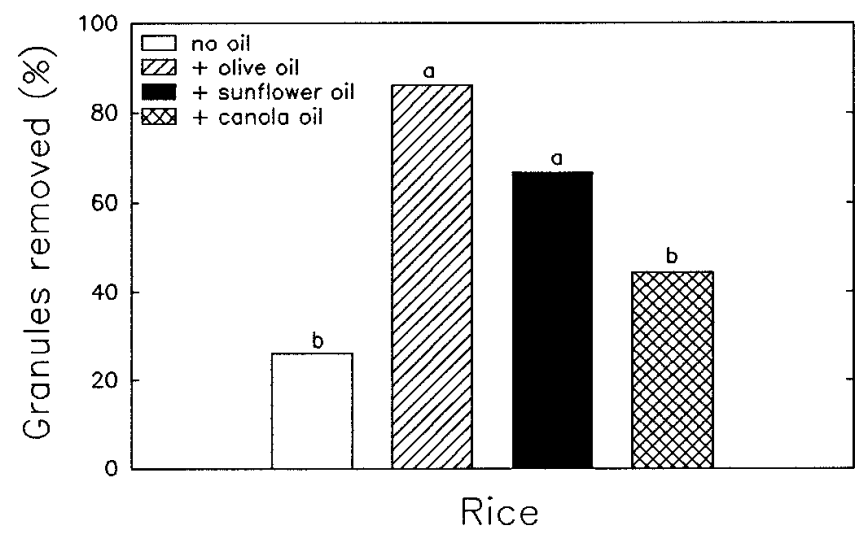

Fig. 3. Effect of addition of various oils to rice formulation on the attraction of Pheidole spp. ants in Beltsville, MD. Rice = alginate granule of rice flour. Percentage represents the portion of the formulation removed in $24 \mathrm{~h}$. Bars with a different letter differ according to a protected least significant difference test $(P \leq 0.05)$. Means are based on combined data from seven experiments.

\section{RESULTS}

Effect of food base on ant attraction to formulations of $\boldsymbol{F}$. oxysporum f. sp. erythroxyli and $F$. oxysporum f. sp. melonis. In field trials in Beltsville, MD, all formulations containing oil attracted ants (Fig. 1). Up to $98 \%$ of C-6 granules were removed within $24 \mathrm{~h}$. The rice flour formulation was only removed when canola oil was added. Significantly fewer granules of the rice without oil formulation were removed by the ants $(P \leq 0.05)$ compared with the other formulations tested. The canola meal formulation did not contain oil, and significantly fewer granules $(P \leq$ $0.05)$ were removed by the ants compared with the C-6 and rice plus canola oil formulations. However, granules with canola meal were more attractive to ants than rice without oil (Fig. 1).

Based on visual observation, population densities of ants in Hawaii appeared larger and ants were more active than those in Maryland. In Hawaii, ants removed more granules than in Maryland, and sometimes these granules were completely removed within $30 \mathrm{~min}$ of being placed in the field. The presence of biomass in any of the formulations tested did not affect the attractiveness to ants (Fig. 2). As with tests in Maryland, significantly fewer rice granules were removed $(P \leq 0.05)$. However, $80 \%$ of rice granules with biomass were removed within $24 \mathrm{~h}$. No difference was found between the two formulations based on wheat flour, C-6, and pesta (Fig. 2). Although the pesta formulation did not contain oil, it was completely removed by ants within $24 \mathrm{~h}$.

Effect of type of oil in formulation on ant preference. In Maryland, rice granules with olive or sunflower oil were preferred equally by ants and were preferred more than rice granules with canola oil or rice alone (Fig. 3). Conversely, in Hawaii, no significant difference in ant removal was found between granules amended with canola or olive oil (Fig. 4). Rice granules without oil were significantly less attractive to ants $(P \leq 0.05)$ than any other formulation tested. Viability of both formae speciales of $F$. oxysporum was not reduced by the oils for at least 1 month after formulations were prepared.

Use of natural materials to deter ants from formulations. All plant products added to the C-6 formulation significantly reduced the number of granules removed compared with the nonamended granules used as controls $(P \leq 0.05)$ (Fig. 5). Chili powder was most effective at repelling ants when it was used at the highest concentration (1:2.5 wt/wt). No significant differences were found between formulations amended with autoclaved or nonautoclaved leaf material from either of the two plants. Granules containing either canna or tansy leaves were not removed by the ants

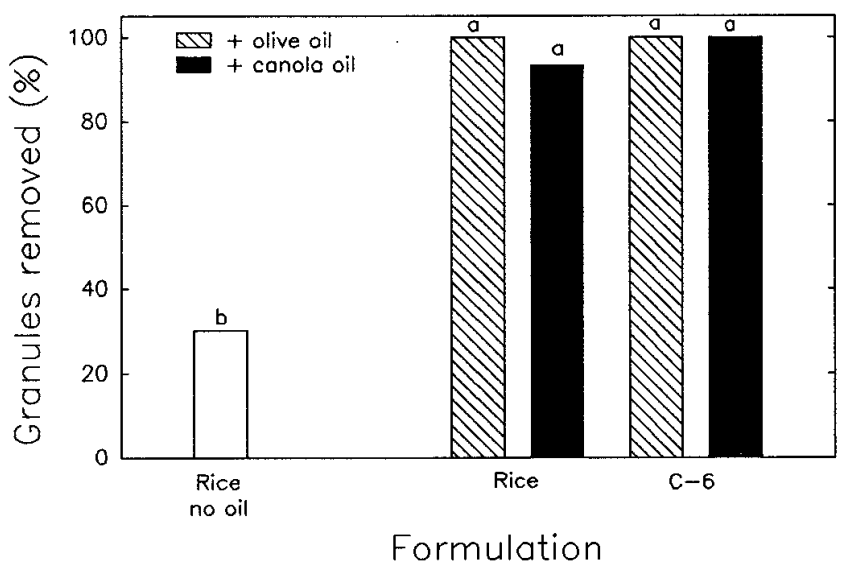

Fig. 4. Effect of addition of various oils to C-6 and rice formulations on the attraction of Pheidole megacephala in Kauai, HI. C-6 = extrusion of wheat plus rice flour, and rice $=$ alginate granule of rice flour. Percentage represents the portion of the formulation removed in $24 \mathrm{~h}$. Bars with a different letter differ according to a protected least significant difference test $(P \leq 0.05)$. Means are based on combined data from four experiments. 
for up to 6 days in the field. Viability of $F$. oxysporum f. sp. erythroxyli was not affected by either canna or tansy leaves. However, chili powder added at the high concentration significantly reduced the counts of $\mathrm{CFU}$ from $1 \times 10^{7}$ to $2.5 \times 10^{6} \mathrm{CFU}$ per $\mathrm{g}$ of formulation.

Ant dispersal of $\boldsymbol{F}$. oxysporum f. sp. erythroxyli through soil. Ants were seen taking the C-6 granules inside their nest during the course of the experiment. In field plots, there was a significant effect $(P \leq 0.05)$ of soil depth on the number of CFU of $F$. oxysporum f. sp. erythroxyli (EN-4 colony type) recovered. Greater population sizes $\left(1.2 \times 10^{5} \mathrm{CFU}\right.$ per $\mathrm{g}$ of dry soil) were found in soil samples from the lower level $(6$ to $9 \mathrm{~cm}$ ) compared with the upper levels ( 0 to 3 and 3 to $6 \mathrm{~cm} ; 2.1$ and $2.9 \times 10^{4} \mathrm{CFU}$ per $\mathrm{g}$ of dry soil, respectively) of the soil cores taken from the ant nests. In tests with tubs, there was no significant effect of soil depth on the recovery of $F$. oxysporum f. sp. erythroxyli (EN-4 colony type). However, the number of CFU was slightly greater in the top 0 to $4 \mathrm{~cm}$ $\left(4.9 \times 10^{5} \mathrm{CFU}\right.$ per $\mathrm{g}$ of dry soil) than in the bottom 4 to $8 \mathrm{~cm}(1.6 \times$ $10^{5} \mathrm{CFU}$ per $\mathrm{g}$ of dry soil).

Ants as carriers of propagules of $F$. oxysporum f. sp. erythroxyli. Significantly $(P \leq 0.05)$ greater numbers of propagules were found in the water used to wash ants incubated in tubs infested with granules with $F$. oxysporum f. sp. erythroxyli $\left(2.5 \times 10^{5}\right.$ propagules per $\mathrm{ml})$ than from tubs with control granules $\left(3.9 \times 10^{4}\right.$ propagules per $\mathrm{ml}$ ). Some $F$. oxysporum $\mathrm{f}$. sp. erythroxyli-type colonies were recovered from ants in the control treatment because this soil was naturally infested with $F$. oxysporum f. sp. erythroxyli. Hyphae grew out of ant bodies collected from $F$. oxysporum f. sp. erythroxyli-infested tubs and plated on FSM within $48 \mathrm{~h}$. After 5 to 10 days of incubation, colonies could be identified as $F$. oxyspor$u m \mathrm{f}$. sp. erythroxyli. The percentage of washed ants carrying propagules of $F$. oxysporum f. sp. erythroxyli either within their bodies or tightly adhering to the outside of their bodies was higher from inoculated tubs $(60 \%$ infested) than from control tubs (10\% infested). Visual observation of plated, washed ants indicated that the fungus appeared to emanate from inside the ant bodies. Granules of formulations used as controls, with no propagules of $F$. oxysporum f. sp. erythroxyli added, were colonized by the native strain of $F$. oxysporum f. sp. erythroxyli during the course of these experiments. The native strain was present in this soil at $<10^{2} \mathrm{CFU}$ per $\mathrm{g}$ of dry soil. This may explain why the $F$. oxysporum f. sp. erythroxyli-type colonies were recovered from ants in control tubs.

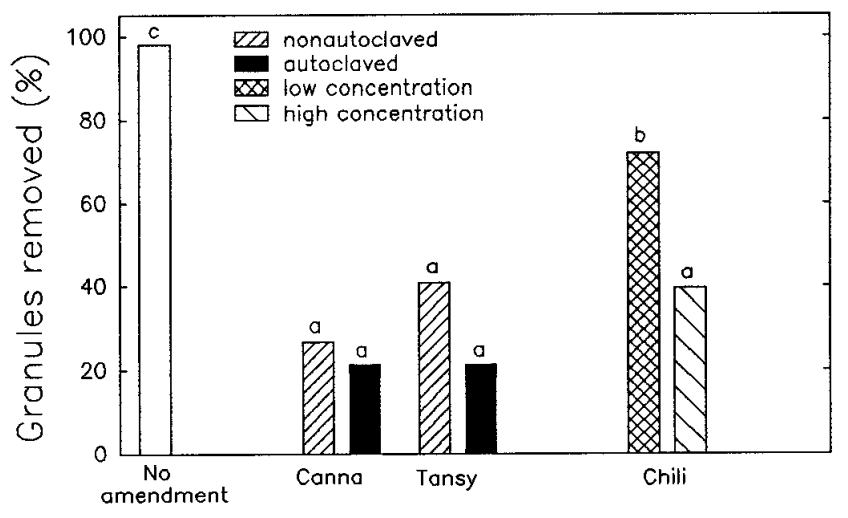

\section{Formulation}

Fig. 5. Effect of addition of plant products to C-6 formulation on Pheidole megacephala preference in Kauai, HI. Canna = dried Canna sp. leaves, tansy $=$ dried Tanacetum vulgare leaves, and chili $=$ commercial chili powder. Autoclaved $=$ leaf material was autoclaved before addition to formulation. Low and high refer to the concentration of chili powder added to C-6 formulation (low $=1: 25[\mathrm{wt} / \mathrm{wt}]$, high $=1: 2.5[\mathrm{wt} / \mathrm{wt}])$. Percentage represents the portion of the formulation removed in $24 \mathrm{~h}$. Bars with a different letter differ according to a protected least significant difference test $(P \leq 0.05)$. Means are based on combined data from five experiments.

\section{DISCUSSION}

Ants of the genus Pheidole are important worldwide $(18,21)$. These ants collect and store seeds, although their diet is very diverse (18). In our study, Pheidole spp. and P. megacephala were attracted to formulations rich in oil content, and formulations without oil were less attractive. The concentration of oleic acid in the oils did not affect ant preference. Although ant preference for size of granules was not specifically tested in our studies, there was no apparent preference by size. C-6 granules were usually the largest and heaviest ( $0.01 \mathrm{~g}$ per granule), while other formulations were smaller and lighter (0.0025 g per granule). Mott and McKeon (17) found that Pheidole spp. preferred the seeds of grass (Themeda australis) to those of legume (Stylosanthes humilis), although both had approximately the same size and weight. However, among Pheidole spp. in the United States, there is a strong correlation between the size of the worker caste and the size of the seed they prefer $(4,8,10)$.

It is not clear whether ants can distinguish different colors (24). A previous study indicated that color of granules (red or blue) did not affect attractiveness of the formulation (7). Although not tested in the current study, no color preference was noted. C-6 is tan in color, rice and pesta are white, and canola is black. Similarly, physical properties of the formulations did not affect ant preference. The extrusion product (C-6) disintegrates more easily than alginate prill. However, the rice alginate formulation was removed as frequently as any extrusion product if oil was present in the alginate formulation.

In our study, addition of canna or tansy leaves to formulations deterred ant removal of formulations. Peterson et al. (20) extracted a strong insect deterrent from fresh canna leaves, although the deterrent product(s) has yet to be characterized. Tanacetin has been isolated from seeds, leaves, and flowers of tansy and may be responsible for the deterrent effect to ants (27). Neither the deterrent product produced by canna nor tansy was inactivated by autoclaving. None of the products tested, except chili powder, affected viability of $F$. oxysporum $\mathrm{f}$. sp. erythroxyli.

Although one of the objectives of this research was to identify formulation additives to deter ant removal of formulation granules from experimental test plots, this removal may be advantageous. Propagules of Fusarium are transported passively through soil by water under most circumstances (6). Vertical movement by water percolation is limited, and soil populations of the fungus are generally greatest in the uppermost $6 \mathrm{~cm}(2,6)$. Ant activity may provide needed dispersal of the fungus throughout the soil, horizontally as well as vertically. In our study, ant activity increased the population size of $F$. oxysporum f. sp. erythroxyli up to a depth of $9 \mathrm{~cm}$ in soil, which may place the fungus in a strategic location for root infection.

In the current study, other arthropods were also observed in association with the formulations, especially large numbers of collembolans. A coleopterous borer was often found on branches of plants that showed symptoms of wilt. Sections of stems, as well as sawdust produced by the feeding activity of these borers, yielded F. oxysporum f. sp. erythroxyli-type colonies when plated on FSM. A close association between the clover root curculio (Sitona hispidulus) and incidence of disease caused by $F$. oxysporum f. sp. medicaginis was reported by Leath and Hower (16). The fungus was consistently isolated from the larvae and adults of the curculio.

Dispersal of biocontrol agents by arthropods may contribute to the effectiveness of mycoherbicides or beneficial microbes used to control diseases. Honey bees have been reported to vector biocontrol agents such as Gliocladium roseum, Epicoccum sp., Pseudomonas fluorescence, and Erwinia herbicola $(13,14,25,26)$. For arthropods to be useful in disseminating biocontrol agents, their biological and ecological characteristics must be taken into consideration. In our experiments, activity of ants was greatest during the morning hours at both locations. Hölldobler and Möglich (11) 
found that, in Pheidole ants, the onset and intensity of foraging was determined by the moisture and temperature of the soil surface. Thus, early morning applications accompanied by ant activity may reduce exposure of the formulations to the harsh climate of the soil surface. Biocontrol formulation research should include assessments of effects on dispersal by arthropods and other organisms.

\section{ACKNOWLEDGMENTS}

We thank C. L. Campbell and the Department of Plant Pathology at North Carolina State University, Raleigh, for the administrative assistance provided to J. Gracia-Garza during completion of this research. We thank S. Poch for producing formulations used in these tests and W. J. Connick, Jr. (USDA, ARS, New Orleans) for providing the pesta formulation. We also thank L. Kennaly, M. Strem, and J. Iwan for their technical assistance.

\section{LITERATURE CITED}

1. Arévalo, E., Zúñiga, L., and Cabezas, O. 1994. Coca plant wilt and its ecological implications in Alto Huallaga. Page 17 in: Resumenes $13^{\circ}$ Congreso Peruano de Fitopatología. Asociación Peruana de Fitopatología, Tingo María, Perú.

2. Bailey, B. A., Hebbar, P. K., and Lumsden, R. D. 1996. Biocontrol of Erythroxylum coca in the field with a formulation of Fusarium oxysporum f. sp. erythroxyli. (Abstr.) Phytopathology 86:S9.

3. Bolton, B. 1994. Identification Guide to the Ant Genera of the World. Harvard University Press, Cambridge.

4. Chew, R. M., and De Vita, J. 1980. Foraging characteristics of a desert ant assemblage: Functional morphology and species separation. J. Arid Environ. 3:75-83.

5. Connick, W. J., Jr., Boyette, C. D., and McAlpine, J. R. 1991. Formulation of mycoherbicides using a pasta-like process. Biol. Control 1:281-287.

6. Gracia-Garza, J. A., and Fravel, D. R. 1996. Effect of relative humidity on sporulation of the mycoherbicide Fusarium oxysporum f. sp. erythroxyli in different formulations and effect of water on spore dispersal. (Abstr.) Phytopathology 86:S85.

7. Gracia-Garza, J. A., Fravel, D. R., Bailey, B. A., and Hebbar, P. K. 1996. Effect of formulation on distribution of the mycoherbicide Fusarium oxysporum f. sp. erythroxyli in the field. (Abstr.) Phytopathology 86:S23.

8. Hansen, S. R. 1978. Resource utilization and coexistence of three species of Pogonomyrmex ants in the Upper Sonoran grassland community. Oecologia 35:109-117.

9. Hebbar, P. K., Lewis, J. A., Poch, S. M., and Lumsden, R. D., 1996. Fermentation and formulation of mycoherbicidal strains of Fusarium oxysporum. (Abstr.) Phytopathology 86:S8-S9.

10. Hölldobler, B. 1976. Recruitment behavior, home range orientation and ter- ritoriality in harvester ants, Pogonomyrmex. Behav. Ecol. Sociobiol. 1:3-44.

11. Hölldobler, B., and Möglich, M. 1980. The foraging system of Pheidole militicida Hymenoptera:Formicidae. Insectes Soc. 27:237-264.

12. Huddleston, E. W., and Fluker, S. S. 1968. Distribution of ant species of Hawaii. Proc. Hawaii. Entomol. Soc. 20:45-69.

13. Israel, M. S., and Boland, G. J. 1992. Influence of formulation on efficacy of honey bees to transmit biological controls for management of sclerotinia stem rot of canola. (Abstr.) Can. J. Plant Pathol. 14:244.

14. Johnson, K. B., Stockwell, V. O., Burgett, D. M., Sugar, D., and Loper, J. E. 1993. Dispersal of Erwinia amylovora and Pseudomonas fluorescens by honey bees from hives to apple and pear blossoms. Phytopathology 83:478-484.

15. Komada, H. 1975. Development of a selective medium for quantitative isolation of Fusarium oxysporum from natural soil. Rev. Plant Prot. Res. $8: 115-125$.

16. Leath, K. T., and Hower, A. A. 1993. Interaction of Fusarium oxysporum f. sp. medicaginis with feeding activity of clover root curculio larvae in alfalfa. Plant Dis. 77:799-802.

17. Mott, J. J., and McKeon, G. M. 1977. A note on the selection of seed types by harvester ants in northern Australia. Aust. J. Ecol. 2:231-235.

18. Naves, M. A. 1985. A monograph of the genus Pheidole in Florida (Hymenoptera:Formicidae). Insecta Mundi 1:53-89.

19. Nelson, A. J., Elias, K. S., Arévalo G., E., and Bailey, B. A. 1996. RAPD analysis of Peruvian isolates of Fusarium oxysporum f. sp. erythroxyli. (Abstr.) Phytopathology 86:S68-S69.

20. Peterson, S. C., Hanson, F. E., and Warthen, J. D., Jr. 1993. Deterrence coding by a larval Manduca chemosensory neurone mediating rejection of a non-host plant, Canna generalis L. Physiol. Entomol. 18:285-295.

21. Reimer, N. J. 1994. Distribution and impact of alien ants in vulnerable Hawaiian ecosystems. Pages 11-22 in: Exotic Ants: Biology, Impact, and Control of Introduced Species. D. F. Williams, ed. Westview Press, Boulder, CO.

22. Sands, D. C., Ford, E. J., Miller, R. V., Sally, B. K., McCarthy, M. K., Anderson, T. W., Weaver, M. B., Morgan, C. T., Pilgeram, A. L., and Darlington, L. C. 1997. Characterization of a vascular wilt of Erythroxylum coca caused by Fusarium oxysporum f. sp. erythroxyli forma specialis nova. Plant Dis. 81:501-504.

23. Steel, R. G. D., and Torrie, J. H. 1980. Principles and Procedures of Statistics. 2nd ed. McGraw-Hill, Inc., New York.

24. Sudd, J. H. 1967. An Introduction to the Behavior of Ants. St. Martin's Press, New York.

25. Sutton, J. C. 1995. Evaluation of micro-organisms for biocontrol: Botrytis cinerea and strawberry, a case study. Pages 173-190 in: Advances in Plant Pathology. J. H. Andrews and I. Tommerup, eds. Academic Press, New York.

26. Thomson, S. V., Hansen, D. R., Flint, K. M., and Vandenberg, J. D. 1992. Dissemination of bacteria antagonistic to Erwinia amylovora by bees. Plant Dis. 76:1052-1056.

27. Windholz, M., ed. 1983. The Merck Index, 10th ed. Merck \& Co. Inc., Rahway, NJ. 